\title{
What is the Best Choice for Urate-lowering Therapy for Korean?
}

\author{
Yun-Hong Cheon, M.D., Ph.D. ${ }^{1}$, Jung Soo Song, M.D., Ph.D. ${ }^{2}$ \\ ${ }^{1}$ Division of Rheumatology, Department of Internal Medicine, Gyeongsang National University School of Medicine, Jinju, ${ }^{2}$ Division of \\ Rheumatology, Department of Internal Medicine, Chung-Ang University School of Medicine, Seoul, Korea
}

Gout is one of the most common forms of acute inflammatory arthritis caused by long-standing hyperuricemia. Various clinical and epidemiological studies have demonstrated that uric acid, which is strongly associated with the pathogenesis of gout, is closely related with increased cardiovascular (CV) risk. Thus, properly controlling uric acid levels within its physiological level using urate-lowering therapy has been hypothesized to improve CV outcomes. Recently, however, on the basis of the results of the largest prospective, the double-blind, randomized controlled trial, entitled "the Cardiovascular Safety of Febuxostat or Allopurinol in Patients with Gout (CARES)," has aroused the possibility of increased CV-related and all-cause mortality in patients receiving febuxostat. Largely on the basis of this unpredicted result, the US and Korea Food and Drug Administration issued a public safety alert concerning the high risk of CV death with the use of febuxostat in February 2019. This unexpected announcement left many rheumatologists confused when they decide the first-line urate-lowering drug in Korea. In this review, we searched for previous studies on uric acid and increased risk of CV disease. In addition, we will introduce various interpretations of the results of the CARES trial and discuss the best choice of urate-lowering therapy for Korean. (J Rheum Dis 2020;27:78-87)

Key Words. Gout, Hyperuricemia, Febuxostat, Allopurinol, Cardiovascular disease

\section{INTRODUCTION}

Gout, the most common form of inflammatory arthritis, is caused by monosodium urate crystals due to longstanding hyperuricemia $[1,2]$. The prevalence and incidence of gout are rapidly increasing worldwide, with consequent, overall increases in the burden of the disease [3-5]. Kim et al. [4] reported that the prevalence and incidence of gout in Korea are 7.58 and 1.94 per 1,000 persons, respectively, based on the Korea National Health Claims data. Furthermore, they predicted an increase in the prevalence and incidence of gout to 16.59 and 3.81 per 1,000 persons in 2025 , respectively. Prolonged predisposing conditions such as asymptomatic hyperuricemia may lead to gout progression and acute gout flares. With proper and lifelong treatment, the disease may not progress to the chronic stage. However, without adequate treatment, gout progresses to chronic tophaceous gout, with repeating intercritical gout and acute gout flares $[1,2,6,7]$. In addition to extremely painful arthritis, various clinical and epidemiological studies have proposed relationships between gout or hyperuricemia, and various comorbidities, including chronic renal diseases, renal stone, diabetes mellitus, hypertension, dyslipidemia, metabolic syndrome, and cardiovascular diseases (CVDs) [8-10]. To control the articular and extra-articular complications of gout, maintaining uric acid level within its physiological level with proper use of uric acid-lowering drugs is important. Unfortunately, a systematic guideline for Koreans has not yet been established [11]. The risk of CVD-related deaths caused by urate-lowering therapy (ULT) reported recently has caused much confusion re-

Received : February 25, 2020, Revised : March 8, 2020, Accepted : March 9, 2020

Corresponding to : Jung Soo Song (iD http://orcid.org/0000-0001-8651-5125

Division of Rheumatology, Department of Internal Medicine, Chung-Ang University School of Medicine, 102 Heukseok-ro, Dongjak-gu, Seoul 06973, Korea. E-mail : drsong@cau.ac.kr 
garding the selection of adequate ULTs $[12,13]$.

This review aimed to examine the relationship between uric acid and CV risk, summarize the treatment pattern of gout in Korea, introduce the background of and results of the Cardiovascular Safety of Febuxostat or Allopurinol in Patients with Gout (CARES) trial, analyze the advantages and disadvantages of the CARES trial, summarize other studies on CVD of xanthine oxidase inhibitors (XOIs), and finally, propose a direction on the type of ULT for patients with gout with various conditions in Korea.

\section{MAIN SUBJECTS}

\section{Uric acid and the risk of cardiovascular disease}

The direct association between gout and the increased risk of CVD is still unclear. However, many studies have demonstrated that uric acid, which is strongly associated with the pathogenesis of gout, increases the risk of CV-related comorbidities, including hypertension, type 2 diabetes mellitus, renal disease, and metabolic syndrome [8-10,14-16]. Uric acid-related comorbidities may be associated with the increased risk of CVD. Furthermore, uric acid itself is a pro-oxidant in endothelial tissue. In long-standing hyperuricemia, excessive reactive oxygen species (ROS) production impairs nitric oxide production and induces endothelial dysfunction, which subsequently increase CVD risk [15-17]. Furthermore, uric acid uptake by vascular smooth muscle cells and adipocytes leads to increased nicotinamide adenine dinucleotide phosphate (NADPH) oxidase activity, stimulating NADPH oxidase-dependent ROS production $[17,18]$. Uric acid also acts as a danger-associated molecular pattern that provokes systemic inflammation. Inflammation itself also affects CVD risk [19]. On the basis of these observations, hyperuricemia is a major independent risk factor for not only gout but also CVD and its related mortality.

However, evidence of a close association between hypouricemia and increased CVD risk is increasing. Recent studies have reported a relationship between lower serum uric acid levels and CVD, showing a U-shaped distribution [20-24]. Lee et al. [24] revealed that both lower and higher serum uric acid levels were associated with an increased 10-year predicted CV risk in men based on data from the Korea National Health and Nutrition Examination Survey (2016 2017). Using data from a single university, Kang et al. [23] also demonstrated that a lower serum uric acid level was an independent risk factor of all-cause mortality in men with normal kidney function.
Although the association between increased CVD risk and hypouricemia is not fully understood, some possible explanations have been proposed. First, uric acid has antioxidant properties in the extracellular environment, including biologic fluid [15,25]. Lee et al. [24] suggested that, as a powerful antioxidant, uric acid scavenges oxygen radicals and protects low-density lipoprotein cholesterol from oxidation, resulting in a protective effect against atherosclerosis $[26,27]$. The loss of antioxidant effect due to low serum uric acid level might increase CVD risk. Second, hypouricemia is a potential predictor of muscle weakness, including sarcopenia. Several studies reported a positive association between serum uric acid levels and handgrip strength and sarcopenia [22,28-31]. The increases in the circulating markers of oxidative stress under the sarcopenic state are also related to CVD risk. On the basis of the above-mentioned data on the relationship between serum uric acid level and CVD, controlling uric acid level within its physiological level using ULTs has been hypothesized to improve $\mathrm{CV}$ outcomes.

\section{Management of gout in Korea}

While it is important to treat and prevent acute flare with colchicine, glucocorticoids, and nonsteroidal anti-inflammatory drugs (NSAIDs), the ultimate strategy to control the symptoms and complications of gout is long-term treatment of hyperuricemia. Controlling hyperuricemia can prevent uric acid from depositing in tissues and normalize serum uric acid levels, which can help prevent the recurrence of articular symptoms and extra-articular complications. Therefore, current worldwide guidelines [32-34] recommend the active use of ULTs to reach and maintain the target uric acid level (Table 1).

The urate-lowering drugs available in Korea are allopurinol and febuxostat, both of which inhibit uric acid formation, and benzbromarone, which promotes urinary excretion of uric acid. Benzbromarone has the advantage of being safe to use in patients with mildly decreased renal function [35]. However, renal stones and fatal hepatotoxicity have been reported in some patients receiving benzbromarone [35-37]. Hence, XOIs are the primary choice of ULT in Korea.

For most patients in whom urate-lowering therapy is indicated, previously we used allopurinol as first-line ULT, typically $100 \mathrm{mg}$ daily with a dose escalation to $100 \mathrm{mg}$ every 2 to 4 weeks to reach the uric acid level below 6 
Table 1. Current recommendations for treatment of hyperuricemia in gout patients

\begin{tabular}{|c|c|c|c|c|}
\hline Guideline/Reference & EULAR (2016) [32] & BSR (2017) [33] & ACR (2012) [34] & ACR (2020 draft) [62] \\
\hline \multicolumn{5}{|c|}{ Current recommendations for asymptomatic hyperuricemia } \\
\hline Lifestyle modification & Yes & Yes & Yes & Yes \\
\hline Urate lowering therapy & No & No & No & No \\
\hline \multicolumn{5}{|c|}{ Current recommendations for acute gout } \\
\hline Initiation of treatment & As early as possible & As early as possible & As early as possible & As early as possible \\
\hline Medications & $\begin{array}{l}\text { NSAIDs, Colchicine, cort } \\
\text { consider IL-1 blocker }\end{array}$ & costeroid (oral, IM, IV), & Combination if needed & Uncontrolled flare up, \\
\hline Colchicine reduction* & Yes & Yes & Yes & Yes \\
\hline Topical ice massage & Recommend & Recommend & Recommend & Recommend \\
\hline \multicolumn{5}{|c|}{ Current recommendations for chronic gout } \\
\hline Target uric acid & $\begin{array}{l}<5 \mathrm{mg} / \mathrm{dL} \text { or }<6 \mathrm{mg} / \mathrm{dL}^{\dagger} \\
\text { No less than } 3 \mathrm{mg} / \mathrm{dL}\end{array}$ & $5 \mathrm{mg} / \mathrm{dL}$ & $\begin{array}{l}<5 \mathrm{mg} / \mathrm{dL} \text { or } \\
<6 \mathrm{mg} / \mathrm{dL}^{\ddagger}\end{array}$ & $<5 \mathrm{mg} / \mathrm{dL}$ or $<6 \mathrm{mg} / \mathrm{dL}$ \\
\hline ULT indications & $\begin{array}{l}\text { Recurrent flares, tophi, } \\
\text { renal stone, arthropathy } \\
\text { Even if } 1 \text { st attack, }<40 \\
\text { years, sUA }>8 \mathrm{mg} / \mathrm{dL} \text {, } \\
\text { comorbidities }\end{array}$ & $\begin{array}{l}\text { Recurrent flares, tophi, } \\
\text { CKD arthropathy, } \\
\text { urolithiasis, diuretics, } \\
\text { young age onset }\end{array}$ & $\begin{array}{l}\text { Recurrent flares, } \\
\text { tophi, CKD 2, } \\
\text { urinary stone }\end{array}$ & $\begin{array}{l}\text { Recurrent flares, tophi, } \\
\text { radiographic damage. } \\
\text { Even if } 1 \text { st attack, CKD } \\
3, \text { sUA }>9 \mathrm{mg} / \mathrm{dL}, \\
\text { urolithiasis }\end{array}$ \\
\hline Commencement of ULT & Not mentioned & After inflammation & During a gout flare & During a gout flare \\
\hline Prophylaxis & Colchicine/NSAIDs & Colchicine/NSAIDs & Colchicine/NSAIDs & Colchicine/NSAIDs \\
\hline Duration of prophylaxis & 6 months & 6 months & $\begin{array}{l}3 \text { months/6 months } \\
\text { (tophi) }\end{array}$ & $\begin{array}{l}3 \text { months/6 months } \\
\text { (tophi) }\end{array}$ \\
\hline HLA-B5801 screening & Not mentioned & $\begin{array}{l}\text { Korean, Han Chinese, } \\
\text { Thai }\end{array}$ & $\begin{array}{l}\text { Korean, Han } \\
\text { Chinese, Thai }\end{array}$ & $\begin{array}{l}\text { Korean, Han Chinese } \\
\text { and Thai, African } \\
\text { American }\end{array}$ \\
\hline 1st line ULT & Allopurinol & Allopurinol & $\begin{array}{r}\text { Allopurinol/ } \\
\text { Febuxostat }\end{array}$ & Allopurinol \\
\hline 2nd line ULT & $\begin{array}{l}\text { Febuxostat or } \\
\text { Uricosuric agents }\end{array}$ & $\begin{array}{l}\text { Febuxostat or } \\
\text { Uricosuric agents }\end{array}$ & Probenecid & $\begin{array}{l}\text { Febuxostat over } \\
\text { probenecid }\end{array}$ \\
\hline 3rd line ULT & Pegloticase & Pegloticase & Pegloticase & Pegloticase \\
\hline
\end{tabular}

EULAR: Eeuropean league against rheumatism, BSR: British society for rheumatology, ACR: American college of rheumatology, NSAIDs: non-steroidal anti-inflammatory drugs, IM: intramuscular, IV: intravenous, IL: interleukin, CKD: chronic kidney disease, ULT: urate-lowering therapy. ${ }^{*}$ Colchicine should be used with caution and at low doses in patients taking drugs that are potent inhibitors of cytochrome P4503A4 (e.g., cimetidine, clarithromycin, erythromycin, fluoxetine, ketoconazole, protease inhibitors, tolbutamide) or p-glycoprotein (e.g., clarithromycin, ciclosporin, erythromycin). ${ }^{\dagger}$ A lower serum uric acid $(<5 \mathrm{mg} / \mathrm{dL})$ is recommended for patients with severe gout (tophi, chronic arthropathy, frequent attacks) in EULAR group recommendation. ${ }^{\ddagger}$ The target serum urate level should be lowered to below $5 \mathrm{mg} / \mathrm{dL}$ in patients with visible tophi or chronic renal impairment.

$\mathrm{mg} / \mathrm{dL}$ [11]. However, skin side effects such as skin rash and hives were frequently reported, and some patients, especially Asians, experienced fatal side effects such as allopurinol-induced severe cutaneous adverse reaction (SCAR). In addition, allopurinol is one of the drugs that frequently induce SCAR and death in Korea [38]. Therefore, since July 2016, febuxostat, another XOI, has also been approved as a first-line urate-lowering drug in Korea. Unlike allopurinol, febuxostat does not have a purine base, and is metabolized mainly in the liver and is excreted equally through the feces and urine. Therefore, the dose in patients with moderate hepatic and renal dysfunction need not be adjusted [39]. Furthermore, febuxostat has rarely been reported to cause hypersensitivity and skin problems, including SCAR. Clinical studies have shown that febuxostat reduces uric acid level more rapidly and effectively than allopurinol [40-44]. Considering its fast effect and low side effect, febuxostat is currently the most preferred drug for hyperuricemia in Korea. However, the CARES trial, a recent large-scale randomized controlled trial (RCT), insisted that febuxostat increased CV-related and all-cause mortality in gout pa- 
tients with CV risk as compared with allopurinol [45]. Owing to the unexpected and frightening results of febuxostat, many rheumatologists are confused as to which drug is suitable as first-line ULT in Korea.

\section{Background and results of the CARES study}

As febuxostat reduced elevated uric acid levels, a risk factor of CVD, more significantly than allopurinol, febuxostat was not expected to increase $\mathrm{CV}$ events more than allopurinol does [46]. Although the results were not statistically significant, the febuxostat-treated patients reported a slightly higher number of CVD events than the allopurinol-treated patients in three published RCTs, as follows: APEX (febuxostat, allopurinol and placebo-controlled study in gout patients) [41], FOCUS (safety and efficacy study of 40, 80, and $120 \mathrm{mg}$ of febuxostat for 5 years) [44], and EXCEL (long-term safety study between febuxostat 80 and $120 \mathrm{mg}$ and allopurinol in gout patient) [43].

Definitive conclusions regarding CV safety, however, could not be drawn from the earlier trials because the number of events was too small for drawing meaningful conclusions. Thus, a phase 3, double-blind RCT was performed to confirm the safety of febuxostat. The CONFIRMS study [47] examined the comparative urate-lowering effect and safety between febuxostat (40 or $80 \mathrm{mg}$ ) and allopurinol (300 mg) in a larger number of patients with gout $(\mathrm{N}=2,269)$. This study analyzed the occurrence of adverse events that met the antiplatelet trialists collaboration (APTC) criteria, such as CV death, nonfatal myocardial infarction, and nonfatal stroke, and non-APTC CV adverse events, including coronary revascularization, transient ischemic attack, congestive heart failure, and arrhythmia. The differences in the rates of the adjudicated non-APTC CV events between the two groups were not statistically significant $(1.32 \%$ for $40 \mathrm{mg}$ febuxostat, $80 \mathrm{mg} 1.19 \%$ for febuxostat, and $0.93 \%$ for allopurinol). The assessed APTC CV event rates were $0.0 \%$ (95\% confidence interval [CI] 0.000 0.486) $40 \mathrm{mg}$ for febuxostat, $0.4 \%$ ( $95 \%$ CI $0.082 \sim 1.155)$ for $80 \mathrm{mg}$ febuxostat (one patient experienced nonfatal myocardial infarction and two patients experienced nonfatal stroke), and $0.4 \%$ (95\% CI 0.082 1.155) for allopurinol (two CV-related deaths) $[13,47]$. Although this was a short-term stability test, after the CONFIRMS trial, the US Food and Drug Administration (FDA) approved febuxostat in 2009 for the regulation of uric acid level in patients with gout; however, additional studies comparing the CV safety of febuxostat and allopurinol in gout patients with $\mathrm{CV}$ risk factors were requested $[13,46]$. Therefore, a multicenter, randomized, double-blind, non-inferiority post-marketing trial was conducted from April 2010 to May 2017 to compare the $\mathrm{CV}$ outcomes of febuxostat therapy with those of allopurinol therapy in patients with gout and CVD.

In the CARES study, 6,190 gout patients with established CV diseases were included and followed up for a median of 32 months. The baseline characteristics, including disease duration, $\mathrm{CV}$ risk factors, and $\mathrm{CV}$ history in two groups (febuxostat and allopurinol), were well balanced. No differences in primary end-points (first occurrence of $\mathrm{CV}$ death, nonfatal myocardial infarction, nonfatal stroke, or urgent revascularization for unstable angina) were observed (hazard ratio [HR], 1.03; 95\% CI, $0.87 \sim 1.23$ ). However, all-cause (HR, 1.22; $95 \mathrm{CI}, 1.01 \sim$ 1.47) and C mortality (HR, 1.34; 95\% CI, $1.03 \sim 1.73$ ) were higher in the febuxostat group than in the allopurinol group. Moreover, sudden cardiac death occurred more frequently in the febuxostat group (2.7\%) than in the allopurinol group (1.8\%). On the basis of these results, the authors of the CARES trial insisted that febuxostat has a higher risk of $\mathrm{CV}$ mortality than allopurinol [45].

\section{Strength and weakness of the CARES RCT}

Unlike previous observational cohort studies of XOIs and CV outcomes, the CARES study was the largest prospective double-blind, RCT to directly compare CV outcomes between allopurinol and febuxostat. Furthermore, this study evaluated the effectiveness and safety of high-dose allopurinol (above $300 \mathrm{mg}$ per day) in patients with renal dysfunction, in which $33.6 \%$ of patients in the allopurinol group received more than $400 \mathrm{mg}$ per day (400 mg; 25.2\%, $500 \mathrm{mg} ; 4.3 \%$, and $600 \mathrm{mg} ; 6.1 \%$ ). The results indicated that, with kidney function monitoring, cautiously increasing allopurinol dose might be safe and effective in patients with renal impairment [13].

Although the CARES RCT is the largest trial that directly compared $\mathrm{CV}$ outcome between febuxostat and allopurinol, several uncertainties and biases remain in this study. First, an attrition bias is possible. In the study, more than half of the participants discontinued the trial regimen (56.6\%) and follow-up (45.0\%) during the study. In addition, an additional 199 deaths (allopurinol, $\mathrm{n}=110$ and febuxostat, $\mathrm{n}=89$ ) were reported by a search company (Omni Trace) after termination of the study. 
Post hoc analysis that included these additional deaths showed that the HR of all-cause mortality between the two groups was not statistically significant (HR, 1.09; $95 \% \mathrm{CI}, 0.94 \sim 1.28)[12,13,45,48]$. Second is the possibility of risks of exaggeration and belief that allopurinol is good for CVD, whereas febuxostat has adverse effects on CVD. As no placebo-controlled group was included in the study, we cannot judge whether increased mortality is directly related to febuxostat or not. If both allopurinol and febuxostat have a protective effect to prevent CVD as compared with placebo or other urate-lowering drugs, the increased CV-related mortality risk of febuxostat in the study might not be a big issue $[13,44]$. Third is selection bias. Post hoc subgroup analyses of CV mortality revealed a more frequent use of NSAIDs and less frequent use of low-dose aspirin among patients who died in the febuxostat group than among those who died in the allopurinol group (NSAID use: $4.8 \%$ vs. $2.2 \%, \mathrm{p}=0.032$; low-dose aspirin use: $3.3 \%$ vs. $3.8 \%, p=0.001$ ). An approximately twofold higher CV mortality rate was observed in patients randomly assigned to febuxostat without aspirin or taking NSAIDs than in those who were receiving allopurinol without aspirin or with low-dose aspirin. No difference in CV mortality was observed among the febuxostat and allopurinol users not taking NSAIDs and taking low-dose aspirin [12]. Lastly, the causal relationship between XOIs and CV mortality is vague. Among the 442 all-cause deaths, only 63 events developed during the on-demand period and $85 \%$ of events occurred after discontinuation. Johnson et al. [49] reported a mean incidence rate of $\mathrm{CV}$ deaths among patients at risk of $0.17 \%$ per month for febuxostat and $0.085 \%$ per month during the CARES trial, which increased 18.7 - and 18.4 -fold to $2.19 \%$ and $1.56 \%$ per month, respectively, for febuxostat and allopurinol, respectively, during the first 30 days after treatment discontinuation. The reason for the increased rate of major adverse cardiac events after discontinuation of XOI treatment remains unclear; however, the possible explanations include "xanthine oxidase withdrawal syndrome," in which the cardioprotective effects disappear upon XOI withdrawal [49]. Furthermore, uric acid levels may rebound after XOI discontinuation, which leads to excessive production of ROS related to CVD. A second possible explanation is the "sick-stopper effect" based on a sharply increased mortality rate within 30 days after drug discontinuation in which worsening of other comorbidities may lead to study drug discontinuation and cause poor clinical outcomes [50]. These findings indicate that XOIs are not the only culprit in CV-related deaths.

\section{Subsequent studies that compared febuxostat and allopurinol}

Following the CARES trial, several studies have compared the CV safety of febuxostat and allopurinol (Table 2) [51-59]. Similar to the CARES trial, one cohort study of gout patients given allopurinol $(n=44,111)$ and febuxostat $(n=44,111)$ that used Taiwan National Health insurance data indicated that febuxostat increased the CV mortality as compared with allopurinol (HR, 1.19; 95\% CI, 1.03 1.36) [51]. However, several other studies showed no such association. A retrospective study using US Medicare claims data reported no significant difference in the risk of myocardial infarction, stroke, new-onset heart failure, and coronary revascularization between 24,936 febuxostat initiators and 74,808 allopurinol initiators among a cohort of 77,774 older Medicare patients with gout. Moreover, all-cause mortality also did not differ between the two groups (HR, 0.95; 95\% CI, 0.89 1.02) [53]. Recently, data from another prospective RCT, Febuxostat for Cerebral and Cardiorenovascular Events Prevention Study (FREED), were published. This trial recruited elderly patients aged 65 years or older who had hyperuricemia and high CV risk to compare the incidences of cerebral, CV, renal events, and all-cause deaths (the primary composite event) between patients treated with febuxostat $(n=537)$ and those treated with drugs besides febuxostat, including allopurinol $(n=533)$. The primary composite event rate was significantly lower in the febuxostat group than in the non-febuxostat treatment group (HR, 0.75; 95\% CI, 0.59 0.95; $\mathrm{p}=0.017$ ) [59]. Despite the controversial results of febuxostat-related $\mathrm{CV}$ risk, both the US and Korean FDAs issued a public safety alert in February 2019 concerning the higher risk of CV death with febuxostat $[60,61]$. In addition, the 2020 American College of Rheumatology (ACR) draft guidelines strongly recommend allopurinol over other ULTs as the preferred first-line agent for all gout patients, including those with CKD stage 3 or worse. They also conditionally recommended that patients receiving febuxostat with a history of CVD or a new CVD-related event switch to an alternative oral ULT if available [62]. 
Table 2. Representative studies for CV related mortality risk between febuxostat and allopurinol or placebo

\begin{tabular}{|c|c|c|c|c|c|}
\hline Design & Population & Exposure & comparator & End points & $\begin{array}{l}\text { CV outcome (febuxostat compared to } \\
\text { allopurinol) }\end{array}$ \\
\hline $\begin{array}{l}\text { RCT/ } \\
\text { White et al. [45] }\end{array}$ & Gout with CVD & $\begin{array}{l}\text { Febuxostat } \\
\qquad(\mathrm{n}=3,098)\end{array}$ & $\begin{array}{l}\text { Allopurinol } \\
(\mathrm{n}=3,092)\end{array}$ & $\begin{array}{l}\text { CV death, nonfatal } \\
\text { MI, stroke, } \\
\text { revascularization }\end{array}$ & $\begin{array}{l}\text { CV mortality } \\
\text { (HR 1.34, 95\% Cl } 1.03 \sim 1.73) \\
\text { All-cause mortality } \\
\quad(\text { HR } 1.22,95 \% \text { Cl } 1.01 \sim 1.47)\end{array}$ \\
\hline $\begin{array}{l}\text { Cohort/ } \\
\text { Su et al. [51] }\end{array}$ & Gout & $\begin{array}{l}\text { Febuxostat } \\
\qquad(\mathrm{n}=44,111)\end{array}$ & $\begin{array}{l}\text { Allopurinol } \\
\qquad(\mathrm{n}=44,111)\end{array}$ & $\begin{array}{l}\text { MACEs, VTE, } \\
\text { HF/AF, CV death, } \\
\text { all-cause mortality }\end{array}$ & $\begin{array}{l}\text { CV mortality } \\
(\text { HR } 1.19,95 \% \mathrm{Cl} 1.03 \sim 1.36) \\
\text { HF (HR } 1.22,95 \% \mathrm{Cl} 1.13 \sim 1.33)\end{array}$ \\
\hline $\begin{array}{l}\text { SR \& Meta-analysis/ } \\
\text { Cuenca et al. [52] }\end{array}$ & $\begin{array}{l}25 \mathrm{RCT} \text { and } 10 \\
\text { meta-analysis }\end{array}$ & $\begin{array}{l}\text { Febuxostat } \\
\qquad(\mathrm{n}=8,602)\end{array}$ & $\begin{array}{l}\text { Allopurinol } \\
(\mathrm{n}=5,118)\end{array}$ & $\begin{array}{l}\text { MACE \& CV } \\
\text { mortality }\end{array}$ & $\begin{array}{l}\text { CV death } \\
\text { (RR } 1.29,95 \% \text { Cl } 1.01 \sim 1.66 \text { ), } \\
\text { (if, excluded CARES [RR 0.73, 95\% } \\
\mathrm{Cl} 0.24 \sim 2.25] \text { ) }\end{array}$ \\
\hline $\begin{array}{l}\text { Cohort/ } \\
\text { Zhang et al. [53] }\end{array}$ & $\begin{array}{l}\text { Gout } \\
\text { (Medicare data) }\end{array}$ & $\begin{array}{l}\text { Febuxostat } \\
\qquad(\mathrm{n}=24,936)\end{array}$ & $\begin{array}{l}\text { Allopurinol } \\
\qquad(\mathrm{n}=74,808)\end{array}$ & $\begin{array}{l}\text { MI or stroke, } \mathrm{HF}, \\
\text { all-cause mortality }\end{array}$ & $\begin{array}{l}\text { All-cause mortality } \\
\text { (HR 0.95, 95\% Cl 0.89 1.02) } \\
\text { HF exacerbation (HR 0.93) }\end{array}$ \\
\hline $\begin{array}{l}\text { Cohort/ } \\
\text { Ju et al. [54] }\end{array}$ & $\begin{array}{l}\text { Gout } \\
\text { (Hong Kong) }\end{array}$ & $\begin{array}{l}\text { Febuxostat } \\
(\mathrm{n}=276)\end{array}$ & $\begin{array}{l}\text { Allupurinol } \\
\qquad(\mathrm{n}=828)\end{array}$ & $\begin{array}{l}\text { MACE } \\
\text { all-cause mortality }\end{array}$ & $\begin{array}{l}\text { All-cause mortality } \\
(\text { HR } 0.99,95 \% \mathrm{Cl} 0.73 \sim 1.33)\end{array}$ \\
\hline $\begin{array}{l}\text { Cohort/ } \\
\text { Kang et al. [55] }\end{array}$ & Gout (KNHIS) & $\begin{array}{l}\text { Febuxostat } \\
\qquad(n=9,910)\end{array}$ & $\begin{array}{l}\text { Allopurinol } \\
\qquad(\mathrm{n}=39,640)\end{array}$ & $\begin{array}{l}\mathrm{MI} / \text { Stroke/TIA } \\
\text { attack or } \\
\text { revascularization, } \\
\text { mortality }\end{array}$ & $\begin{array}{l}\text { All-cause mortality } \\
(\text { HR } 0.96,95 \% \mathrm{Cl} 0.79 \sim 1.16)\end{array}$ \\
\hline $\begin{array}{l}\text { RCT/ } \\
\text { Kimura et al. [56] }\end{array}$ & $\begin{array}{l}\text { Hyperuricemia } \\
\text { with CKD } 3\end{array}$ & $\begin{array}{l}\text { Febuxostat } \\
(\mathrm{n}=219)\end{array}$ & $\begin{array}{l}\text { Placebo } \\
\qquad(\mathrm{n}=222)\end{array}$ & $\begin{array}{l}\text { Renal function } \\
\text { and CV event }\end{array}$ & No difference for death \\
\hline $\begin{array}{l}\text { Cohort/ } \\
\text { Chen et al. [57] }\end{array}$ & Gout & $\begin{array}{l}\text { Febuxostat } \\
\qquad(\mathrm{n}=5,278)\end{array}$ & $\begin{array}{l}\text { Allopurinol } \\
(\mathrm{n}=5,278)\end{array}$ & $\begin{array}{l}\text { Hypersensitivity, } \\
\text { CVD }\end{array}$ & $\begin{array}{l}\text { CVD risk } \\
(\mathrm{HR} 1.16,95 \% \mathrm{Cl} 0.95 \sim 1.41)\end{array}$ \\
\hline $\begin{array}{l}\text { Cohort/ } \\
\text { Foody et al. [58] }\end{array}$ & $\begin{array}{c}\text { Gout with CKD } 3 \\
\text { or } 4 \text { and CVD }\end{array}$ & $\begin{array}{l}\text { Febuxostat } \\
(\mathrm{n}=370)\end{array}$ & $\begin{array}{l}\text { Allopurinol } \\
(\mathrm{n}=2,056)\end{array}$ & Major CV event & $\begin{array}{l}\text { Major CV event } \\
(\text { HR } 0.52,95 \% \mathrm{Cl} 0.30 \sim 0.91)\end{array}$ \\
\hline $\begin{array}{l}\text { RCT/ } \\
\text { Kojima et al. [59] }\end{array}$ & $\begin{array}{l}\text { Hyperuricemia } \\
\text { with CV or } \\
\text { renal disease }\end{array}$ & $\begin{array}{l}\text { Febuxostat } \\
(\mathrm{n}=537)\end{array}$ & $\begin{array}{l}\text { Others } \\
(n=537)\end{array}$ & $\begin{array}{l}\text { Fatal and non-fatal } \\
\mathrm{CV} \text {, renal event } \\
\text { and death }\end{array}$ & $\begin{array}{l}\text { All-cause mortality } \\
(\text { HR } 0.75,95 \% \mathrm{Cl} 0.59 \sim 0.95)\end{array}$ \\
\hline
\end{tabular}

CV: cardiovascular, RCT: randomized controlled trial, SR: systematic review, CVD: cardiovascular disease, KNHIS: Korean National Health Insurance Service, CKD: chronic kidney disease, MI: myocardial infarction, MACE: major adverse cardiac event, VTE: venous thromboembolism, HF: heart failure, AF: atrial fibrillation, TIA: transient ischemic attack, HR: hazard ratio, Cl: confidence interval, RR, relative risk, CARES: the Cardiovascular Safety of Febuxostat or Allopurinol in Patients with Gout.

\section{As recommended in the FDA black-box warning and 2020 ACR draft guidelines, should we again choose allopurinol as the primary drug for control- ling hyperuricemia in gout patients, unlike the cur- rent treatment?}

We recommend a "wait-and-see" approach. The most significant impact on the FDA recommendations was largely based on the results of the CARES trial; however, Asians comprised only $3 \%$ of the CARES trial participants [45]. In this regard, direct implementation of the findings to Korean patients may result in problems due to ethnic differences. Therefore, urate-lowering drugs should be selected on the basis of the results of studies performed in Korean patients. Kang et al. [55] used 2002 2015
Korean National Health Insurance Service data for the entire Korean population to conduct a comparative study of $\mathrm{CV}$ occurrence and all-cause mortality between the two drugs, with a 4:1 propensity score matching of 39,640 allopurinol initiators and 9,910 febuxostat initiators. Even though middle-aged patients (mean age, 59 years) were mostly enrolled, this Korean population-based study indicated no difference in the risk of non-fatal CV events and all-cause mortality between allopurinol and febuxostat initiators. Second, the selection of urate-lowering drugs in Korea must consider the risk of allopurinol-induced SCAR. In 2019, the Korean SCAR consortium conducted a retrospective study of 123 patients enrolled in the Korean SCAR registry between 2011 and 2016 to 
identify the drugs that induced drug rash with eosinophilia and systemic symptoms (DRESS) syndrome. The results showed that allopurinol induced DRESS syndrome most frequently $(n=28)$ [38]. HLA-B*5801, which is closely related to SCAR, is highly expressed especially in Korean, Han Chinese, and Thai populations [34,63]. In one study of Koreans, $12.2 \%$ of the total study population was positive for HLA-B*5801 and $92 \%$ of allopurinol-induced SCARS cases were positive for HLA-B*5801, indicating the association between SCAR and HLA-B*5801 (odds ratio [OR] $=98.0$ ) [64]. In a retrospective cohort analysis using HLA genotype data in patients with chronic renal failure among Koreans taking allopurinol, SCAR occurred in $18 \%$ of patients with chronic renal failure who were positive for HLA-B*5801 [65]. A 2019 review of 13 RCTs analyzed the differences in mortality and adverse skin reaction between febuxostat and allopurinol in patients with gout or asymptomatic hyperuricemia (sample size: 13,539 patients). This review found no significant difference in the increase of cardiac-related mortality between febuxostat and allopurinol (OR, 0.72; 95\% CI, 0.24 2.13; $\mathrm{p}=0.55$ ) and a significantly lower incidence of adverse skin reactions in the febuxostat group (OR, 0.72; 95\% CI, 0.55 0.96; $\mathrm{p}=$ 0.02). In a subgroup analysis, they separately analyzed Asian and Western data. The non-Asian subgroup of patients who were receiving febuxostat showed higher $\mathrm{CV}$-related mortality than those who were receiving allopurinol (OR, 1.31; 95\% CI, 1.01 1.71). However, we found no significant difference in CV-related mortality between the two drugs (OR, 0.73; 95\% CI, 0.17 3.23). The occurrence of cutaneous adverse reactions was significantly lower in the Asian patients who were using febuxostat (OR, 0.25; 95\% CI, 0.11 0.58) [66].

\section{CONCLUSION}

Gout is a chronic inflammatory disease that can cause articular pain and deformation, as well as CVD. Both hyperuricemia and hypouricemia can increase the risk of CVD; therefore, maintaining uric acid level within its physiological level by monitoring while taking uric acid-lowering drugs will help prevent and control complications such as CVD.

Unlike Westerners, Asians are at a higher risk of skin hypersensitivity reactions and renal impairment by allopurinol than of CVD by febuxostat. In addition, most patients currently using febuxostat have not reached the target uric acid level with allopurinol, have side effects caused by allopurinol, or have renal dysfunction. Therefore, a sudden change to allopurinol due to the risk of CVD may actually further increase CVD risk due to a sudden increase in uric acid level.

Therefore, we present the following framework for the determination of the use of urate-lowering drugs for gout patients in Korea.

1. The choice of urate-lowering drugs should be made after close consultation between the patient and the physician.

2. Physicians should select drugs on the basis of sufficient consideration of the patient's underlying disease.

3. In patients without renal dysfunction or underlying CVD, low doses of febuxostat (20 or $40 \mathrm{mg}$ ) or allopurinol (100 mg/day) should be started, and dose escalation should be determined after evaluating responses and adverse events.

4. HLA-B*5801 testing should be performed before starting allopurinol therapy for patients with CKD stage 3 or higher. However, difficulties exist in terms of the current national health insurance coverage for this test and shortage of institutes that perform the test. If the HLA-B*5801 test is not available, we recommend starting low-dose febuxostat therapy as the first-line ULT.

5. We recommend starting low-dose allopurinol or febuxostat therapy for patients with high CV risk, that is, a history of CVD or stroke, or two or more risk factors of CVD (hypertension, type 2 diabetes mellitus, CKD, metabolic syndrome, etc.), after close consultation between the patient and physician. The physician should inform patients of the possible CV risk with febuxostat or allopurinol therapy. If the patient is already taking one of the XOIs, we recommend using the previous drug.

Future prospective studies on urate-lowering drugs, CVD, and related mortality in Koreans are urgently required.

\section{CONFLICT OF INTEREST}

No potential conflict of interest relevant to this article was reported.

\section{AUTHOR CONTRIBUTIONS}

J.S.S. was in charge of conception and design of study and analysis of data. Y.H.C. was responsible for collection data, drafting and revising the manuscript. All authors 
made an effort for writing manuscript.

\section{REFERENCES}

1. Dalbeth N, Merriman TR, Stamp LK. Gout. Lancet 2016; 388:2039-52.

2. Richette P, Doherty M, Pascual E, Barskova V, Becce F, Castaneda J, et al. 2018 updated European League Against Rheumatism evidence-based recommendations for the diagnosis of gout. Ann Rheum Dis 2020;79:31-8.

3. Elfishawi MM, Zleik N, Kvrgic Z, Michet CJ Jr, Crowson CS, Matteson EL, et al. The rising incidence of gout and the increasing burden of comorbidities: a population-based study over 20 years. J Rheumatol 2018;45:574-9.

4. Kim JW, Kwak SG, Lee H, Kim SK, Choe JY, Park SH. Prevalence and incidence of gout in Korea: data from the National Health Claims Database 2007-2015. Rheumatol Int 2017;37:1499-506.

5. Kuo CF, Grainge MJ, Mallen C, Zhang W, Doherty M. Rising burden of gout in the UK but continuing suboptimal management: a nationwide population study. Ann Rheum Dis 2015;74:661-7.

6. McGill NW. Gout and other crystal-associated arthropathies. Baillieres Best Pract Res Clin Rheumatol 2000;14:445-60.

7. Shiozawa A, Szabo SM, Bolzani A, Cheung A, Choi HK. Serum uric acid and the risk of incident and recurrent gout: a systematic review. J Rheumatol 2017;44:388-96.

8. Choi HK, Ford ES, Li C, Curhan G. Prevalence of the metabolic syndrome in patients with gout: the Third National Health and Nutrition Examination Survey. Arthritis Rheum 2007;57:109-15.

9. Jung JH, Song GG, Ji JD, Lee YH, Kim JH, Seo YH, et al. Metabolic syndrome: prevalence and risk factors in Korean gout patients. Korean J Intern Med 2018;33:815-22.

10. Kuo CF, Grainge MJ, Mallen C, Zhang W, Doherty M. Comorbidities in patients with gout prior to and following diagnosis: case-control study. Ann Rheum Dis 2016;75: 210-7.

11. Choi HJ, Lee CH, Lee JH, Yoon BY, Kim HA, Suh CH, et al. Current gout treatment and flare in South Korea: prophylactic duration associated with fewer gout flares. Int J Rheum Dis 2017;20:497-503.

12. Abeles AM, Pillinger MH. Febuxostat and the black box blues. ACR Open Rheumatol 2019;1:343-4.

13. Choi H, Neogi T, Stamp L, Dalbeth N, Terkeltaub R. New perspectives in rheumatology: implications of the cardiovascular safety of febuxostat and allopurinol in patients with gout and cardiovascular morbidities trial and the associated Food and Drug Administration public safety alert. Arthritis Rheumatol 2018;70:1702-9.

14. Liu SC, Xia L, Zhang J, Lu XH, Hu DK, Zhang HT, et al. Gout and risk of myocardial infarction: a systematic review and meta-analysis of cohort studies. PLoS One 2015;10: e0134088.

15. Kim SK. Interrelationship of uric acid, gout, and metabolic syndrome: focus on hypertension, cardiovascular disease, and insulin resistance. J Rheum Dis 2018;25:19-27.

16. Kang EH, Kim SC. Cardiovascular safety of urate lowering therapies. Curr Rheumatol Rep 2019;21:48.

17. Huang KH, Tai CJ, Tsai YF, Kuan YH, Lee CY. Correlation between gout and coronary heart disease in Taiwan: a nationwide population-based cohort study. Acta Cardiol Sin 2019;35:634-40.

18. Sautin YY, Nakagawa T, Zharikov S, Johnson RJ. Adverse effects of the classic antioxidant uric acid in adipocytes: NADPH oxidase-mediated oxidative/nitrosative stress. Am J Physiol Cell Physiol 2007;293:C584-96.

19. Braga TT, Forni MF, Correa-Costa M, Ramos RN, Barbuto JA, Branco P, et al. Soluble uric acid activates the NLRP3 inflammasome. Sci Rep 2017;7:39884.

20. Tseng WC, Chen YT, Ou SM, Shih CJ, Tarng DC; Taiwan Geriatric Kidney Disease (TGKD) Research Group. U-shaped association between serum uric acid levels with cardiovascular and all-cause mortality in the elderly: the role of malnourishment. J Am Heart Assoc 2018;7:e007523.

21. Kuo CF, See LC, Yu KH, Chou IJ, Chiou MJ, Luo SF. Significance of serum uric acid levels on the risk of all-cause and cardiovascular mortality. Rheumatology (Oxford) 2013;52:127-34.

22. Cho SK, Chang Y, Kim I, Ryu S. U-shaped association between serum uric acid level and risk of mortality: a cohort study. Arthritis Rheumatol 2018;70:1122-32.

23. Kang E, Hwang SS, Kim DK, Oh KH, Joo KW, Kim YS, et al. Sex-specific relationship of serum uric acid with all-cause mortality in adults with normal kidney function: an observational study. J Rheumatol 2017;44:380-7.

24. Lee SY, Park W, Suh YJ, Lim MJ, Kwon SR, Lee JH, et al. Association of serum uric acid with cardiovascular disease risk scores in Koreans. Int J Environ Res Public Health 2019;16:E4632.

25. Ames BN, Cathcart R, Schwiers E, Hochstein P. Uric acid provides an antioxidant defense in humans against oxidantand radical-caused aging and cancer: a hypothesis. Proc Natl Acad Sci U S A 1981;78:6858-62.

26. So A, Thorens B. Uric acid transport and disease. J Clin Invest 2010;120:1791-9.

27. Johnson RJ, Kang DH, Feig D, Kivlighn S, Kanellis J, Watanabe $\mathrm{S}$, et al. Is there a pathogenetic role for uric acid in hypertension and cardiovascular and renal disease? Hypertension 2003;41:1183-90.

28. Kawamoto R, Ninomiya D, Kasai Y, Kusunoki T, Ohtsuka $\mathrm{N}$, Kumagi $\mathrm{T}$, et al. Serum uric acid is positively associated with handgrip strength among Japanese community-dwelling elderly women. PLoS One 2016;11:e0151044.

29. Beavers KM, Beavers DP, Serra MC, Bowden RG, Wilson $\mathrm{RL}$. Low relative skeletal muscle mass indicative of sarcopenia is associated with elevations in serum uric acid levels: findings from NHANES III. J Nutr Health Aging 2009;13: 177-82.

30. Can B, Kara O, Kizilarslanoglu MC, Arik G, Aycicek GS, Sumer F, et al. Serum markers of inflammation and oxidative stress in sarcopenia. Aging Clin Exp Res 2017;29: 745-52.

31. Lee J, Hong YS, Park SH, Kang KY. High serum uric acid level is associated with greater handgrip strength in the aged population. Arthritis Res Ther 2019;21:73.

32. Richette P, Doherty M, Pascual E, Barskova V, Becce F, Castañeda-Sanabria J, et al. 2016 updated EULAR evidence-based recommendations for the management of gout. Ann Rheum Dis 2017;76:29-42.

33. Hui M, Carr A, Cameron S, Davenport G, Doherty M, 
Forrester $\mathrm{H}$, et al.; British Society for Rheumatology Standards, Audit and Guidelines Working Group. The British Society for Rheumatology Guideline for the management of gout. Rheumatology (Oxford) 2017;56:1246.

34. Khanna D, Khanna PP, Fitzgerald JD, Singh MK, Bae S, Neogi T, et al.; American College of Rheumatology. 2012 American College of Rheumatology Guidelines for management of gout. Part 2: therapy and antiinflammatory prophylaxis of acute gouty arthritis. Arthritis Care Res (Hoboken) 2012;64:1447-61.

35. Azevedo VF, Kos IA, Vargas-Santos AB, da Rocha Castelar Pinheiro G, Dos Santos Paiva E. Benzbromarone in the treatment of gout. Adv Rheumatol 2019;59:37.

36. Ye X, Wu J, Tang K, Li W, Xiong C, Zhuo L. Benzbromarone as a possible cause of acute kidney injury in patients with urolithiasis: two case reports. Medicine (Baltimore) 2019;98: e15214.

37. Zhang MY, Niu JQ, Wen XY, Jin QL. Liver failure associated with benzbromarone: a case report and review of the literature. World J Clin Cases 2019;7:1717-25.

38. Sim DW, Yu JE, Jeong J, Jung JW, Kang HR, Kang DY, et al.; Korean Severe Cutaneous Adverse Reactions Consortium. Variation of clinical manifestations according to culprit drugs in DRESS syndrome. Pharmacoepidemiol Drug Saf 2019;28:840-8.

39. Grewal HK, Martinez JR, Espinoza LR. Febuxostat: drug review and update. Expert Opin Drug Metab Toxicol 2014; 10:747-58.

40. Becker MA, Schumacher HR Jr, Wortmann RL, MacDonald PA, Palo WA, Eustace D, et al. Febuxostat, a novel nonpurine selective inhibitor of xanthine oxidase: a twenty-eight-day, multicenter, phase II, randomized, double-blind, placebo-controlled, dose-response clinical trial examining safety and efficacy in patients with gout. Arthritis Rheum 2005;52:916-23.

41. Schumacher HR Jr, Becker MA, Wortmann RL, Macdonald PA, Hunt B, Streit J, et al. Effects of febuxostat versus allopurinol and placebo in reducing serum urate in subjects with hyperuricemia and gout: a 28-week, phase III, randomized, double-blind, parallel-group trial. Arthritis Rheum 2008;59:1540-8.

42. Becker MA, Schumacher HR Jr, Wortmann RL, MacDonald PA, Eustace D, Palo WA, et al. Febuxostat compared with allopurinol in patients with hyperuricemia and gout. $\mathrm{N}$ Engl $\mathrm{J}$ Med 2005;353:2450-61.

43. Becker MA, Schumacher HR, MacDonald PA, Lloyd E, Lademacher C. Clinical efficacy and safety of successful longterm urate lowering with febuxostat or allopurinol in subjects with gout. J Rheumatol 2009;36:1273-82.

44. Schumacher HR Jr, Becker MA, Lloyd E, MacDonald PA, Lademacher C. Febuxostat in the treatment of gout: 5-yr findings of the FOCUS efficacy and safety study. Rheumatology (Oxford) 2009;48:188-94.

45. White WB, Saag KG, Becker MA, Borer JS, Gorelick PB, Whelton A, et al.; CARES Investigators. Cardiovascular safety of febuxostat or allopurinol in patients with gout. $\mathrm{N}$ Engl J Med 2018;378:1200-10.

46. White WB, Chohan S, Dabholkar A, Hunt B, Jackson R. Cardiovascular safety of febuxostat and allopurinol in patients with gout and cardiovascular comorbidities. Am Heart J 2012;164:14-20.
47. Becker MA, Schumacher HR, Espinoza LR, Wells AF, MacDonald P, Lloyd E, et al. The urate-lowering efficacy and safety of febuxostat in the treatment of the hyperuricemia of gout: the CONFIRMS trial. Arthritis Res Ther 2010;12:R63.

48. Katsiki N, Borghi C. The future of febuxostat after the Cardiovascular Safety of Febuxostat and Allopurinol in Patients with Gout and Cardiovascular Morbidities (CARES) trial: who cares? Expert Opin Pharmacother 2018;19: 1853-6.

49. Johnson TA, Kamatani N, Kuwabara M. Xanthine oxidase inhibitor withdrawal syndrome? Comment on the article by Choi et al. Arthritis Rheumatol 2019;71:1966-7.

50. Ghang B, Ahn SM, Kim J, Kim YG, Lee CK, Yoo B. Discontinuing febuxostat might cause more deaths than continuing febuxostat: the untold story from the CARES trial. Rheumatology (Oxford). 2019 Nov 21 [Epub]. DOI: 10.1093/rheumatology/kez552.

51. Su CY, Shen LJ, Hsieh SC, Lin LY, Lin FJ. Comparing cardiovascular safety of febuxostat and allopurinol in the real world: a population-based cohort study. Mayo Clin Proc 2019;94:1147-57.

52. Cuenca JA, Balda J, Palacio A, Young L, Pillinger MH, Tamariz L. Febuxostat and cardiovascular events: a systematic review and meta-analysis. Int J Rheumatol 2019;2019: 1076189.

53. Zhang M, Solomon DH, Desai RJ, Kang EH, Liu J, Neogi T, et al. Assessment of cardiovascular risk in older patients with gout initiating febuxostat versus allopurinol: population-based cohort study. Circulation 2018;138:1116-26.

54. Ju C, Lai RWC, Li KHC, Hung JKF, Lai JCL, Ho J, et al. Comparative cardiovascular risk in users versus non-users of xanthine oxidase inhibitors and febuxostat versus allopurinol users. Rheumatology (Oxford) 2019 Dec 24 [Epub]. DOI: 10.1093/rheumatology/kez576.

55. Kang EH, Choi HK, Shin A, Lee YJ, Lee EB, Song YW, et al. Comparative cardiovascular risk of allopurinol versus febuxostat in patients with gout: a nation-wide cohort study. Rheumatology (Oxford) 2019;58:2122-9.

56. Kimura K, Hosoya $T$, Uchida S, Inaba M, Makino $H$, Maruyama S, et al.; FEATHER Study Investigators. Febuxostat therapy for patients with stage $3 \mathrm{CKD}$ and asymptomatic hyperuricemia: a randomized trial. Am J Kidney Dis 2018;72: 798-810.

57. Chen CH, Chen CB, Chang CJ, Lin YJ, Wang CW, Chi CC, et al. Hypersensitivity and cardiovascular risks related to allopurinol and febuxostat therapy in Asians: a populationbased cohort study and meta-analysis. Clin Pharmacol Ther 2019;106:391-401.

58. Foody J, Turpin RS, Tidwell BA, Lawrence D, Schulman KL. Major cardiovascular events in patients with gout and associated cardiovascular disease or heart failure and chronic kidney disease initiating a xanthine oxidase inhibitor. Am Health Drug Benefits 2017;10:393-401.

59. Kojima S, Matsui K, Hiramitsu S, Hisatome I, Waki M, Uchiyama K, et al. Febuxostat for cerebral and CaRdiorenovascular events PrEvEntion StuDy. Eur Heart J 2019;40:1778-86.

60. U.S. Food and Drug Administration. FDA adds boxed warning for increased risk of death with gout medicine uloric (febuxostat) [Internet]. Silver Spring (MD): U.S. Food and Drug Administration, c2017 [cited 2020 Feb 18]. Available from: 
https://www.fda.gov/DRugs/DrugSafety/ucm631182.htm.

61. Ministry of Food and Drug Safety. Safety information of febuxostat [Internet]. Cheongju: Ministry of Food and Drug Safety, c2019 [cited 2020 Feb 18]. Available from: https:// nedrug.mfds.go.kr/pbp/CCBAC01/getItem? safeLetterNo $=289$.

62. American College of Rheumatology. 6W025 Gout management: new ACR Clinical Guideline [Internet]. Atlanta (GA): American College of Rheumatology, c2020 [cited 2020 Feb 18]. Available from: https://plan.core-apps.com/tristar_acr19/ event/dd3623777338a651afd0e05cf7ba0b1b.

63. Hung SI, Chung WH, Liou LB, Chu CC, Lin M, Huang HP, et al. HLA-B*5801 allele as a genetic marker for severe cutaneous adverse reactions caused by allopurinol. Proc Natl Acad Sci U S A 2005;102:4134-9.
64. Kang HR, Jee YK, Kim YS, Lee CH, Jung JW, Kim SH, et al.; Adverse Drug Reaction Research Group in Korea. Positive and negative associations of HLA class I alleles with allopurinol-induced SCARs in Koreans. Pharmacogenet Genomics 2011;21:303-7.

65. Jung JW, Song WJ, Kim YS, Joo KW, Lee KW, Kim SH, et al. HLA-B58 can help the clinical decision on starting allopurinol in patients with chronic renal insufficiency. Nephrol Dial Transplant 2011;26:3567-72.

66. Liu CW, Chang WC, Lee CC, Shau WY, Hsu FS, Wang ML, et al. The net clinical benefits of febuxostat versus allopurinol in patients with gout or asymptomatic hyperuricemia a systematic review and meta-analysis. Nutr Metab Cardiovasc Dis 2019;29:1011-22. 